\title{
Occupational aspects of epilepsy in the civil service
}

\author{
Michael Espir, Michael Floyd, John Chaplin
}

\begin{abstract}
Eighty five civil servants with epilepsy who were referred to the Civil Service Occupational Health Service over an 18 month period formed the study population. The reasons for these referrals and their outcomes have been analysed. The main reasons for referral were prolonged or frequent sickness absence, unsatisfactory work performance, epilepsy starting during employment, the discovery of undisclosed epilepsy, and for advice on working conditions. In 30 the outcome was medical retirement, although in only 15 was this due to epilepsy alone. Of the other 15, medical retirement was necessary in four because of the combination of epilepsy with another medical disorder, and in 11 because of a coincidental condition unrelated to their epilepsy. Only six out of 15 referred on account of epilepsy related sickness absence, and none of the 14 referrals due to epilepsy related unsatisfactory work performance resulted in early retirement. This reflected the invaluable role that the occupational physicians had in recognising where problems were due to poor control of the epilepsy or to the side effects of the antiepileptic medication and in arranging through general practitioners or hospital doctors for appropriate adjustment of the drug regimen. Nine of the 22 subjects who developed epilepsy during employment, however, were retired on medical grounds.
\end{abstract}

A study was carried out, in collaboration with the British Civil Service Occupational Health Service (CSOHS), of Civil Service employees with epilepsy. The study was supported by a research contract with the Health and Safety Executive's Medical Services Division and a research grant from the British Epilepsy Research Foundation. The aim of our study was to examine the factors relevant to the health, safety, and performance at work of civil servants with epilepsy, whose medical and personnel files were

Rehabilitation Resource Centre, Department of Systems Science, City University, Northampton Square, London EC1 V 0HB, Great Britain M Espir, M Floyd, J Chaplin available to the CSOHS. The three key factors on which the study was concentrated were (1) medical, (2) employment, and (3) social.

At the time of the study there were nearly 600000 civil servants, and about 50000 referrals a year were made by government departments to the CSOHS for advice. Most concerned sickness absence and were dealt with using case files. About 4000 medical retirement certificates for civil servants were issued annually by the CSOHS.

About 50000 new entrants a year were recruited to the non-industrial Civil Service, and the case files of about $20 \%$ were referred to the CSOHS for advice about fitness for employment. The Civil Service recruitment procedure requires each candidate to complete a health declaration form (HDF) that is separate from the job application form and is inspected only after the candidate has been selected subject to satisfactory health.

Those disclosing on their HDF that they have had fits, fainting attacks, blackouts, or epilepsy are referred to the CSOHS for advice about their medical fitness for appointment; rejection on health grounds is only possible on medical advice to this effect.

The subjects with epilepsy who were referred to the CSOHS were divided into two categories:

(1) Those referred on recruitment as having disclosed epilepsy on their HDF-called "recruitment" cases.

(2) Those referred during the course of their employment because of a medical problem or query-called "health problem" cases.

This paper deals with the occupational aspects of the "health problem" cases.

\section{Methods}

The subjects were obtained with the help of the CSOHS medical and nursing advisers, who were asked to notify the research team of each employee with epilepsy who was referred with a health problem during the 18 months from November 1985 to May 1987. Documents made available to the research teams were:

The medical file-Each civil servant has a medical file, which should contain the sickness absence record and personnel officer's minutes. When necessary, reports are obtained with the patient's consent from the 
general practitioner, hospital doctor, consultant referee, or a local medical officer (who is an independent general practitioner instructed to examine the subject in or near his or her home area and report to the CSOHS).

Recruitment papers-Including HDF.

Welfare reports-These are provided by a civil service welfare officer regarding occupational, social and other factors considered relevant to the individual's health problem.

Documents and correspondence relating to past and present referrals to the CSOHS.

The annual (or probationary) report-This is completed by the employee's immediate supervisor in conjunction with higher management. The details are agreed with the employee during annual interviews. It contains information about work performance and prospects for promotion, recommendations for improvement, and comments about the employee.

Each civil servant with epilepsy who was referred was also sent a postal questionnaire that sought information on the employee's epilepsy, the employment history and current employment situation, and the social situation. Fixed format questions were used in the questionnaire to make completing it as easy as possible. Each questionnaire was assigned an individual study number to preserve the anonymity of the subject.

Twelve medical officers were responsible for giving advice on occupational health matters to all government departments and any queries about cases with epilepsy referred to occupational health nurses were passed on to the doctor dealing with the subject's department. Usually queries were answered and advice was given by the doctor from study of the case files, but if necessary employees would be called or sent for examination. If cases were referred more than once, the same doctor, the one dealing with the employee's department, was usually involved. One of us (ME) was one of the Civil Service medical officers and was in close touch with colleagues, which ensured as far as possible that all referrals were notified to the research team.

Although no detailed guidelines were used by the Civil Service medical officers, the accepted policy was to consider each case individually, to ensure that optimum medical treatment was being given and that all appropriate measures were taken to enable employees to continue in employment. Working conditions were modified if necessary and checked to see that they were satisfactory and safe. For medical retirement from the Civil Service strict criteria had to be fulfilled-the Medical Adviser had to certify that the employee was suffering from a medical condition preventing him or her from discharging the normal duties of the post and that the effects were likely to be permanent.

\section{Results}

During the study period 93 subjects with epilepsy were referred to the CSOHS but eight were withheld because of some sensitivity or objection by the employees or their personnel officers. The results therefore are based on 85 subjects ( 51 men, 34 women), 45 of whom returned completed questionnaires. Table 1 shows the demographic data of the 85 subjects and table 2 gives details about their epilepsy. Fourteen of the subjects were registered as disabled on account of their epilepsy.

Information on the reasons for referral was obtained for each subject, and for 31 advice was sought on more than one occasion; this resulted in 119 requests for advice. Table 3 shows the six main reasons for referral, the numbers in each category, and the outcome of these referrals. These are examined in detail in the subsequent sections.

\section{PROLONGED OR FREQUENT SICKNESS ABSENCE}

Twenty six referrals were due to prolonged or frequent sickness absence. Only six were because of absence that stemmed from epilepsy alone. This led to the medical retirement of two subjects. In three of the other four, the subjects were able to return to work after changes were made to the drug regimen or when duties were modified or restricted. One subject was still on sick leave at the last follow up.

In nine referrals the sickness absence was related to epilepsy and another disorder. This led to the medical retirement of four subjects. One of these had

Table 1 Age, marital state, grade, and duration of employment in the Civil Service of 85 ( 51 men, 34 women) civil servants with epilepsy

\begin{tabular}{llll}
\hline Age $(y)(N o)$ & Marital state (No) & Grade (No) & Duration of service (y) (No) \\
\hline $18-20(2)$ & Single (50) & Executive officer (9) & Less than 2(37) \\
$21-30(30)$ & Married (33) & Clerical officer (24) & $2-5(26)$ \\
$31-40(21)$ & Divorced (2) & Clerical assistant (29) & $6-10(13)$ \\
$41-50(20)$ & & Messenger, security officer, manual worker, others (23) & More than 10 (9) \\
$51-60(10)$ & & & \\
$61-65(2)$ & & & \\
\hline
\end{tabular}


Table 2 Types and frequency of seizures, age of onset of epilepsy, and number of antiepileptic drugs (AEDs) taken per subject

\begin{tabular}{llll}
\hline Types of seizures (No) & Frequency of seizures (No) & Age at onset (y) (No) & No of AEDs (No) \\
\hline Generalised tonic clonic (45) & More than one a week (18) & $0-15(41)$ & $0(1)$ \\
Generalised and partial (30) & One a week-one a month (20) & $16-30(27)$ & $1(43)$ \\
Complex partial (4) & One per month-one & $31-60(17)$ & $2(37)$ \\
Others (6) & every six months (7) & & $3(4)$ \\
& One every six months- & & \\
& one in last year (20) & & \\
& None in last year (20) & & \\
\hline
\end{tabular}

a wrist operation resulting in significant time off work; one was off work for a lengthy period with a schizophrenic illness; and two had anxiety states that kept them off work on several occasions. The remaining five referrals returned to work. One of these, who had recently been recruited, was on prolonged sick leave partly because of complications arising after an appendix operation; and two were off sick due to a variety of minor disorders. One of these improved after treatment was stabilised, another was referred to a specialist, and two continued to have frequent sickness absence; one of these subjects subsequently resigned; the other is still in employment.

Eleven referrals were made because of sickness absence entirely unrelated to epilepsy. A wide variety of disorders was involved-namely, sciatica (two cases), abdominal disorder, depression and alcoholism, cancer, impaired memory not attributable to medication, a heart attack, peripheral vascular disease and diabetes, and chronic leukaemia. In one other case, the subject was allowed absence to care for his wife who had had a heart attack; he should have been given compassionate rather than sick leave. Eight of these subjects were retired early on grounds of ill health. The other two continued in employment. We do not believe that these decisions were influenced by the fact that they had epilepsy.

It was not possible to determine the outcome in the case of one other referral who did not have a medical disorder.

\section{UNSATISFACTORY WORK PERFORMANCE}

Twenty three referrals were due to unsatisfactory performance at work. In 14 this was directly linked to the subject's epilepsy, and in 10 of these their performance was adversely affected by frequent or disabling fits at work. In three their poor performance was more a consequence of the side effects of their antiepileptic medication. In one referral, the problem was actually agoraphobia, thought to be due to anxiety about having a fit in public.

In the other nine, the inadequate performance at work seemed to be unrelated to their epilepsy. In four cases the poor performance appeared to be related to another disorder-namely, a heart condition, diabetes, alcohol abuse, and depression. In five the poor performance could not be attributed to epilepsy or to any other medical disorder. In only four referrals, retirement on the grounds of ill health was recommended as a consequence of unsatisfactory work performance. In none of them was there any evidence that epilepsy was the cause of the poor standard of work.

In two other referrals the employees were still on probation and it was decided that their appointments should be terminated. In one of these, however, the employee appealed against the decision and the probation period was extended. Two other cases, in which epilepsy was not implicated, resulted in the termination of employment because they resigned.

In the other 10 cases, the subjects remained in

Table 3 The reasons for the referrals, the number in each category, and their outcomes

\begin{tabular}{|c|c|c|c|c|}
\hline Reason for referral & Medical retirement & Continued in work & Other or not known & Total \\
\hline $\begin{array}{l}\text { Prolonged or frequent sickness absence: } \\
\text { Due only to epilepsy } \\
\text { Due to epilepsy and another disorder } \\
\text { Not due to epilepsy }\end{array}$ & $\begin{array}{l}2 \\
4 \\
8\end{array}$ & $\begin{array}{l}3 \\
5 \\
2\end{array}$ & $\begin{array}{l}1 \\
0 \\
1\end{array}$ & $\begin{array}{r}6 \\
9 \\
11\end{array}$ \\
\hline $\begin{array}{l}\text { Unsatisfactory work performance: } \\
\text { Due to epilepsy } \\
\text { Not due to epilepsy }\end{array}$ & $\begin{array}{l}0 \\
4\end{array}$ & $\begin{array}{r}12 \\
3\end{array}$ & $\begin{array}{l}2 \\
2\end{array}$ & $\begin{array}{r}14 \\
9\end{array}$ \\
\hline Epilepsy starting during employment & 9 & 12 & 1 & 22 \\
\hline $\begin{array}{l}\text { Undisclosed epilepsy discovered during } \\
\text { employment }\end{array}$ & 1 & 7 & 0 & 8 \\
\hline Advice on working conditions & 2 & 28 & 5 & 35 \\
\hline Annual health review & 0 & 3 & 2 & 5 \\
\hline Total & 30 & 75 & 14 & 119 \\
\hline
\end{tabular}


employment and various measures were recommended with a view to improving their performance. These included changes in drug treatment, a move to another job, and giving longer to learn the job.

\section{EPILEPSY DEVELOPING DURING EMPLOYMENT IN THE CIVIL SERVICE}

Twenty two referrals were made for advice due to the onset of epilepsy during employment in the Civil Service.

Nine of these resulted in subjects being retired on the grounds of ill health. For one other, restrictions were placed on the duties the subject could perform and he subsequently resigned. Thus 12 , over half of those referred, continued in employment after their epilepsy was diagnosed. In seven, however, the medical officer recommended that their duties should be restricted in some way to avoid an accident if a seizure occurred.

PRE-EXISTING BUT UNDISCLOSED EPILEPSY DISCOVERED IN CIVIL SERVICE

Eight subjects were found to have had epilepsy diagnosed before their recruitment to the Civil Service, but had not disclosed this on the HDF. Only one was retired on grounds of ill health. The other seven continued in employment, although in some, their duties were restricted.

\section{ADVICE ON WORKING CONDITIONS}

Thirty five referrals were made to obtain medical advice regarding the suitability of work of 34 subjects. Twenty two were to ascertain whether some restriction should be placed on the work done to try and avoid danger of an accident resulting from a seizure, four were at the request of the subjects, six were due to concern about the possibility of an epileptic seizure being triggered by work with a visual display unit (VDU), one was to ascertain the suitability of working in a hazardous environment (forestry) and two were to ascertain whether disciplinary action might exacerbate their epilepsy.

Only two of this group were retired on grounds of ill health, and in only one was this because there appeared to be no way of eliminating the risk of an accident. Employment was terminated in three other cases.

Twenty eight of the 34 subjects remained in employment. For seven this was possible because improvements in their medical treatment led to their epilepsy being better controlled. For four, duties had to be restricted. Of these four, one was allowed to carry out only indoor duties, and was barred from driving and working with machinery, one was not allowed to work near or with machinery, and was barred from climbing ladders, one was removed from a rota that involved working alone at an outstation and one was removed from a security roster.
Of the four referrals to the medical adviser made at the request of the employee, two had the restrictions placed on them removed, one had a transfer to a less stressful job approved, and the other had a request for transfer from messenger to security guard refused.

Of the six who were referred for advice regarding work on a VDU, three were deemed suitable. For the other three, a recommendation that they should not be allowed to work with a VDU was made following advice from their general practitioners.

The subject who was referred for advice regarding suitability for work in a hazardous environment (forestry) was allowed to continue in employment but was moved to a management position.

For the two subjects for whom disciplinary action was being considered medical advice was that this was not likely to exacerbate their epilepsy.

\section{ANNUAL HEALTH REVIEW}

New entrants to the Civil Service who disclose epilepsy can be appointed in an unestablished (health) category. Their appointments are then subject to review by the CSOHS after one to four years. If reports and sickness absence records are then satisfactory, establishment is approved.

Five subjects with epilepsy who had been appointed in the unestablished (health) category, were referred for their annual review during the period of study and are included because they had also had recent health problems.

Three of these subjects continued to work for the Civil Service, two on extended probation, the other in an established position. Of the two on extended probation, one had quite severe seizures and was transferred to an office close to relatives where stress levels were likely to be lower and the other improved her work performance after a change of medication. The third subject believed she was sensitive to VDU equipment, which the department intended to introduce. It was found on consultation with her general practitioner that she was not photosensitive and she was given an established position. Two other subjects did not continue in the Civil Service. One of them felt unable to do the work and left voluntarily before review. The other had frequent and severe seizures (one or two major fits a week). The medical officer considered that the subject's condition was incompatible with the duties expected of her and the probationary period was terminated.

\section{Discussion}

Although the prevalence of disclosed epilepsy among those recruited can be calculated, we have not studied the prevalence of epilepsy or of other medical disorders in established civil servants in view of the inherent difficulties in collecting such confidential 
information. Civil Service statistics on sickness absence and medical retirement data are available but it would not be justifiable to make any inference about prevalence from these, as they include only those referred to the CSOHS with work related problems. Nevertheless the preponderance of our subjects in lower grades and absence of any in the higher echelons is noteworthy.

It has not been possible to compare the results of this study with others, as no comparable examination of referrals to an occupational health department appears to have been carried out. It is, however, possible to put forward a number of tentative conclusions, based upon our findings, and to suggest areas in which similar investigations might be of particular value.

The most obvious finding is that employees with epilepsy have been referred to the CSOHS for many reasons. Much of the published data on epilepsy and employment $^{1}$ tend to emphasise the concern of employers about safety and the possible risks of an accident occurring if someone with epilepsy is employed. This concern, however, was mentioned explicitly in only 23 of the 119 referrals in our study, although it was probably a factor in some of the 22 referrals due to epilepsy starting in employment and also in the eight referrals of undisclosed epilepsy discovered during employment in the Civil Service.

In this study referrals because of a high level of sickness absence and unsatisfactory work performance were equally common, although it needs to be borne in mind that in a substantial proportion of these cases epilepsy was not thought to be the cause of the problem.

It would be wrong to infer from these figures that all employees with epilepsy are likely to experience sickness absence or that their performance at work will be unsatisfactory. In fact our parallel study of people with epilepsy recruited by the Civil Service shows this not to be the case. ${ }^{2}$ Our findings do indicate, however, that overgeneralised claims ${ }^{3}$ that the work performance of people with epilepsy is no different from that of other employees need to be treated with care.

Another finding of interest is the wide variation in the outcome of referrals. Thus over two thirds (eight out of 11) of referrals because of sickness absence not due to epilepsy resulted in early retirement. Less than half (six out of 15) of referrals due to epilepsy related sickness absence, however, were retired early on grounds of ill health, and none of the 14 referred because of epilepsy related poor work performance resulted in early retirement. This reflects the extent to which the CSOHS medical officers were able to play a significant part through general practitioners and hospital doctors in obtaining optimum control of the employee's epilepsy.

In many of these cases the poor performance was thought to be due to the side effects of the anticonvulsant medication. Here too the CSOHS was able to play an important part by identifying this problem so that the employee's medical regimen could be adjusted to reduce or abolish the side effects that were responsible for the poor performance. ${ }^{4}$

Encouraging though these findings are, the fact that the outcome in 30 of the 85 subjects was early retirement cannot be regarded as satisfactory. Appraisal of some of these cases indicated that whereas every effort was made to improve the management of epilepsy, not enough was done by management and personnel officers to explore ways in which the job itself might be modified or to find possible alternative positions to which the subject might be redeployed. ${ }^{2}$ It is worrying that nearly half (nine out of 22) of the referrals that were made after the onset of epilepsy during employment, should have resulted in early retirement.

We believe that further studies of this kind should be done to see whether similar patterns are found in other organisations; it would also be interesting to investigate in the same way referrals to occupational health departments of employees with other medical disorders.

We acknowledge with thanks the research grant from the British Epilepsy Research Foundation, also the support received from Dr Carter, Dr Gompertz, Dr Felicity Edwards, and Dr Lucas of the Employment Medical Advisory Service of the Health and Safety Executive. We thank the medical and nursing advisers of the CSOHS for their help, and in particular all the civil servants with epilepsy and their departmental personnel officers who made this study possible. We also thank Dr Zarrina Kurtz for helpful discussions during the course of the study, and Robert Levy who dealt with the administration of the project.

Requests for reprints to: Dr M Floyd, Director, Rehabilitation Resource Centre, Department of Systems Science, City University, Northampton Square, London EC1V 0HB, Great Britain.

1 Floyd M. A review of published studies on epilepsy and employment. In: Edwards F, Espir M, Oxley J, eds. Epilepsy and employment. London: Royal Society of Medicine, 1986:3-7.

2 Floyd M, Chaplin J, Espir M, Kurtz Z. The health, safety and performance at work of Civil Service employees with epilepsy. London: Rehabilitation Resource Centre, 1989.

3 Kettle $M$. Disabled people and accidents. Journal of Occupational Accidents 1984;6:277-93.

4 Floyd M, Chaplin J, Espir M, Kurtz Z. The management of epilepsy at work. Int J Rehabil Res 1988;11:3-10.

Accepted 18 February 1991 